\title{
Outcome of cardiovascular risk assessment among rural community dwellers in ezionum, Nigeria-implications for public health
}

\author{
David U Adje ${ }^{1}$, Felicia E Williams², Azuka C Oparah ${ }^{3}$
}

1. Department of Clinical Pharmacy and Pharmacy Administration, Delta State University, Abraka, Nigeria. E mail: a_udave77@yahoo.com

2. Department of Clinical Pharmacy and Pharmacy Practice, University of Ilorin, Nigeria. Email: wilfe2013@gmail.com

3. Department of Clinical Pharmacy and Pharmacy Practice, University of Benin, Benin city, Nigeria. Email:oparaca@yahoo.com

\begin{abstract}
Background: Cardiovascular disease is a major cause of mortality worldwide. Risk assessment has been shown to reduce cardiovascular morbidity and mortality. In view of their proximity and accessibility, community pharmacies could be a suitable site for cardiovascular risk assessment and other preventive health activities especially in rural underserved populations. The objective of this study was to assess outcome of cardiovascular risk assessment among rural community dwellers.

Materials and methods: Five hundred and five community dwellers aged 40 to 80 years were recruited for the study. Cardiovascular risk assessment was performed using the region specific WHO/ISH risk assessment charts. Blood pressure, diabetes status, total non- fasting cholesterol, and age were used to estimate risk category. Demographic variables and clinical characteristics were expressed as frequency and percentage. Regression analysis was done to identify predictors of high risk category.

Results: More than 30\% of subjects were hypertensive. Nearly 30\% were overweight and had abnormal cholesterol levels. The proportion of subjects in the high risk category was $8.9 \%$. Systolic blood pressure, random blood sugar and advancing age were the highest predictors of high risk category.

Conclusion: Accessibility, proximity and availability are unique characteristics of community pharmacies that could be exploited to support community based screening services.

Keywords: Cardiovascular risk assessment, community pharmacy, rural community dwellers, Nigeria.

DOI: https://dx.doi.org/10.4314/ahs.v19i2.35

Cite as: Adje DU, Williams FE, Oparah AC. Outcomes of cardiovascular risk assessment among rural community dwellers in Ezionum, Nigeria-implications for public health. Afri Health Sci.2019;19(2): 2112-2120. bttps:// dx.doi.org/10.4314/abs.v19i2.35

\section{Introduction}

Cardiovascular diseases is a major cause of mortality worldwide. Mortality from cardiovascular disease cuts across age, gender and socio-economic background. ${ }^{1-3}$ Globally, an estimated 17 million persons die annually

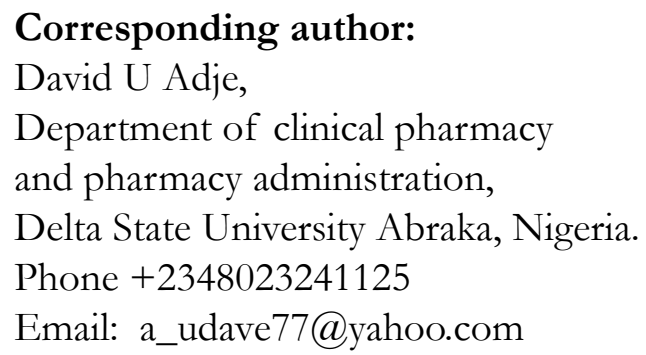

from heart diseases and the figure is projected to rise to 82 million in 2020. ${ }^{4}$ Disability Adjusted Life Years (DALYs) lost due to cardiovascular disease ranks next only to HIV/AIDS. Cardiovascular diseases claim more lives annually than all forms of cancers combined. ${ }^{5}$ Modifiable risk factors for cardiovascular disease include high blood pressure, high levels of serum cholesterol, tobacco use, physical inactivity and obesity. ${ }^{6-7}$ Despite extensive progress in understanding risk factors for cardiovascular disease and advances in therapeutics, cardiovascular disease continues to exert huge toll on humanity. ${ }^{8}$ Risk assessment and interventions have been shown to reduce morbidity and mortality from cardiovascular disease. Absolute or global risk assessment is the preferred option and is of more accurate predictive value since cardiovascular
\end{abstract}


disease results from multiple risk factors acting synergistically to increase a person's overall risk. ${ }^{9}$ Thus a person with several slightly raised risk factors may be at greater risk than a person with just one elevated risk factor.

Absolute cardiovascular risk approach takes into consideration the combined effect of several cardiovascular risk factors and is more likely to be more beneficial and cost effective. ' The world health organization actively promotes the involvement of non- physician health care workers in cardiovascular risk assessment. ${ }^{10}$ Community pharmacists have demonstrated proficiency in interventions relating to risky behaviours, risk reduction and chronic disease management. ${ }^{11-13}$ One of the earliest evidence of effectiveness of pharmacists in this regard was the initiative by the United States Public Health Service (USPHS) which promoted a model for the integration of pharmacy care services into the public health system. ${ }^{14}$ Reductions in cost of care, adverse drug events and cost of care, adverse drug events, hospital admissions and emergency hospital visits were positive outcomes observed in the Navajo seizure clinic and the Ashville Project. ${ }^{14}$ Since the Ashville project, community pharmacists in various countries have continued to demonstrate effectiveness in preventive health and chronic disease management. ${ }^{15}$ Since community pharmacies are located in the heart of community and many apparently healthy people visit community pharmacies on a daily basis, pharmacists are well placed to carry out preventive health activities among individuals and different population groups. The main objective of this study was to assess outcome of cardiovascular risk assessment among rural community dwellers using the WHO/ISH risk assessment tool.

\section{Materials and method Setting}

The setting is Ezionum, a rural community in Ukwuani Local Government Area of Delta State, Nigeria with headquarters located at Obiaruku. The total population of the Local government area is about 103,000. The community is located at latitude 5.72859 longitude $6.23226 .{ }^{17}$ The community has a well-organized primary health center that caters to their health needs. A general hospital located at Obiaruku, about 3 kilometres from the community serves as a referral center for more serious cases. For many years, the community has served as a site for
Community Based Experience and Services (COBES) program for medical and nursing students of the Delta State University. Other NGOs have also used the community for outreach programs. The study is a cross sectional cardiovascular risk assessment among rural community dwellers using the WHO/ ISH cardiovascular risk assessment charts. The study was carried out from August 2015 to March 2016.

\section{Inclusion and exclusion criteria}

The American Heart Association recommends that cardiovascular risk assessment be done for persons aged 40 to 80 years, therefore all persons between age 40 and 80 who expressed a willingness to participate in the study by signing the informed consent form were screened. ${ }^{19}$ Persons below 40 years with very high risk factors were also screened. Persons who did not meet the stipulated criteria were excluded.

\section{Data collection instrument}

The WHO/ISH risk assessment chart was used for the study. This instrument is a validated region specific instrument which makes use of - age, sex, systolic blood pressure, total cholesterol, diabetes and smoking status to assess cardiovascular risk. Colour codes are used to determine the risk score/ category. After selecting the appropriate chart based on an individual's diabetes and smoking status, the point of intersection between the systolic blood pressure and total serum cholesterol values on the chart would fall within a range of colours that is coded to determine cardiovascular risk level. The colour codes range from very high risk to very low risk as follows: Very dark red $=\geq 40 \%$; red $=30-<40 \%$; purple $=20-<30 \%$; yellow $=10-<20 \%$ and green $=<10 \%$. Demographic and clinical characteristics were entered into a data collection form designed for the study. The first part of the form consisted of contact details, age, physical activity status and alcohol consumption habit. Respondents were required to tick options that apply to them on the data collection form. This part could be self-completed if the subject was literate. The second part consisted of clinical data obtained from measurement. Space was provided for the risk score and risk category obtained from the use of the WHO/ISH risk prediction charts.

\section{Data collection procedures}

A series of visits to the King of the clan and his chiefs 
explaining the purpose of the study and the benefit to the community facilitated acceptance by the people. The study commenced at the palace where cardiovascular risk assessment was done for members of the royal household and some prominent chiefs. As focal persons in the community who have already benefited from risk assessment, it was expected that they would encourage and motivate other members of the community to volunteer for the study. Thereafter the health center was used for the main study. The town crier alerted the community through several rounds of announcements each time the team was to come to the community. Eke market day was chosen for the screening activity since there was no farming on that day and residents were likely to be at home and available for the screening exercise. The purpose of the study was explained to the volunteer. If the individual agreed to participate, a written informed consent form was completed and signed.

Blood pressure was measured using an automated BP apparatus (Omron 1A1B). The subject was asked to sit with arm supported on a table so that cuff was at heart level. After resting for about 5 minutes, the cuff was inflated to desired level. The person was asked not to talk during measurement. Two measurements were taken and average recorded.

Total cholesterol was measured using Multi-care cholesterol meter (Biomedical Systems International, Italy). A finger-prick sample was obtained with an automatic lancing device following aseptic procedure. An Acuchek Active (R) glucose meter was used for obtaining blood glucose measurement following a procedure similar to that used in obtaining cholesterol measurement.Waist circumference was measured at midpoint between the top of the iliac crest and the bottom of the ribs using a simple non-elastic measuring tape. Height and weight were measured using a SESCA 213 mobile standiometer and a Camry digital weighing scale. Body mass index was computed using the formula:Weight (kg)/ Hight (M2). Data obtained was recorded on a data collection form designed by the researchers.

\section{Outcome measures}

Outcome measures were: proportion of subjects who were physically active (30 minutes of moderate activity at least 3 times a weekand proportion of subjects who were moderate to high consumers of alcohol, proportion of subjects who use tobacco,proportion of subjects with high systolic and diastolic blood pressure levels,proportion of subjects with high blood glucose levels,proportion of subjects with total cholesterol levels above 5 mmoles/ liter and proportion of subjects with high cardiovascular risk.

\section{Data analysis}

Responses were coded and entered into SPSS software (SPSS () ) version 19.0. ${ }^{17}$ Categorical data were expressed as frequency and percentages. Predictors of dependent variables were identified by performing multinomial logistic regression analysis. Multinomial logistic regression analysis does not require assumption of a liner relationship between dependent and independent variables. It can also accommodate violations of normality. It is most appropriate where the categorical dependent variable has more than 2 categories. ${ }^{18}$ The Exponential Beta value and corresponding $\mathrm{P}$ values were interpreted as the odds of having a high risk score compared to the reference group and the a measure of which independent variables significantly predicts the dependent variable. A $p$ value of less than 0.05 was considered statistically significant.

\section{Results}

The Ezionum community is divided into three sections. All sections of the community were represented in the sample of respondents that presented for screening. A total of 505 respondents were screened. There were more females, 312(61.8\%) than males, 198(38.2). The predominant age group was $61-70$ years, $156(30 \%)$. Only $23(4.6 \%)$ were below 40 years. The proportion smokers was quite small, 18(3.1\%) compared to those that consumed alcoholic beverages, 228, (45.1\%) More than one third of respondents, $174(34.5 \%)$ were physically inactive. More than half, 325(64.4\%) had no coexisting chronic disease condition. Among those with chronic diseases, diabetes was the most prevalent, 158(31.3\%). Demographic details of screened subjects are presented in Table 1. Nearly half, 232(45.9\%) and more than half, 335(66.4\%) had systolic and diastolic blood pressure values respec- 
Table 1 Socio demographics of community dwellers

\begin{tabular}{|c|c|}
\hline Item & Number (\%) \\
\hline \multicolumn{2}{|l|}{ Location } \\
\hline OgbeAweka Quarters & $171(33.8)$ \\
\hline OgbeNnawu Quarters & $119(23.6)$ \\
\hline OgbeOfu quarters & $215(42.6)$ \\
\hline \multicolumn{2}{|l|}{ Sex } \\
\hline Male & $193(38.2)$ \\
\hline Female & $312(61.8)$ \\
\hline \multicolumn{2}{|l|}{ Age (yrs.) } \\
\hline Less than 40 & $23(4.6)$ \\
\hline $40-50$ & $112(22.2)$ \\
\hline $51-60$ & $126(25.0)$ \\
\hline $61-70$ & $156(30.0)$ \\
\hline Above 70 & $88(17.4)$ \\
\hline \multicolumn{2}{|l|}{ Smoking status } \\
\hline Smokers & $18(3.1)$ \\
\hline Non smokers & $487(96.4)$ \\
\hline \multicolumn{2}{|l|}{ Smoking type } \\
\hline Non smoker & $488(96.6)$ \\
\hline Occasional & $7(1.4)$ \\
\hline Moderate ( 1 or 2 daily) & $8(1.6)$ \\
\hline Heavy ( Up to I pack or more daily) & $2(0.4)$ \\
\hline \multicolumn{2}{|l|}{ Ever smoked? } \\
\hline No & $459(90.9)$ \\
\hline Yes & $46(9.1)$ \\
\hline \multicolumn{2}{|l|}{ When stopped smoking } \\
\hline Less than 1 year & $4(0.8)$ \\
\hline More than 1 year & $32(6.3)$ \\
\hline Still smoking & $12(2.4)$ \\
\hline Non smoker & $457(90.5)$ \\
\hline \multicolumn{2}{|l|}{ Alcohol consumption status } \\
\hline Light ( $<2$ glasses/shot occasionally $)$ & $90(17.8)$ \\
\hline Moderate (Few drinks 2 or 3 times a week) & $130(25.7)$ \\
\hline Heavy (Several drinks daily) & $8(1.6)$ \\
\hline Don't drink & $277(54.9)$ \\
\hline \multicolumn{2}{|l|}{ Physical activity $\geq \mathbf{3 0}$ mins a day } \\
\hline Zero time /week & $59(11.7)$ \\
\hline 1 time /week & $23(4.6)$ \\
\hline 2 times/ week & $92(18.2)$ \\
\hline 3 times/ week & $157(31.1)$ \\
\hline Every day & $174(34 . J)$ \\
\hline \multicolumn{2}{|l|}{ Chronic disease* } \\
\hline Hypertension & $105(20.8)$ \\
\hline Diabetes & $158(31.3)$ \\
\hline Stroke & $6(1.2)$ \\
\hline Angina & $10(2.0)$ \\
\hline Asthma & $1(0.2)$ \\
\hline None & $325(64.4)$ \\
\hline
\end{tabular}

tively beyond normal values. Blood glucose and total cholesterol values were elevated for 19, (3.8\%) and $140(29.7 \%)$ of screened subjects respectively, Table 2 . A total of $45(8.9 \%)$ persons were at high 10 year risk of fa- tal or non -fatal cardiovascular events (heart attack, stroke and myocardial infarction), Figure 1

Sex, age, smoking status, alcohol intake, level of physical activity, comorbidity, blood pressure, total cholesterol 
Table 2: Clinical characteristics of community dwellers

\begin{tabular}{|c|c|}
\hline Characteristic & No $(\%)$ \\
\hline \multicolumn{2}{|l|}{ Blood Pressure Systolic } \\
\hline $90-119$ & $103(20.4)$ \\
\hline $120-139$ & $170(33.7)$ \\
\hline $140-159$ & $146(28.9)$ \\
\hline$\geq 160$ & $86(17.0)$ \\
\hline \multicolumn{2}{|l|}{$\overline{\text { Diastolic }}$} \\
\hline $60-69$ & $58(11.5)$ \\
\hline $70-79$ & $112(22.2)$ \\
\hline $80-89$ & $149(29.5)$ \\
\hline $90-99$ & $114(22.6)$ \\
\hline$\geq 100$ & $72(14.3)$ \\
\hline \multicolumn{2}{|l|}{ Heart rate( bpm) } \\
\hline $50-69$ & $83(16.4)$ \\
\hline $70-79$ & $159(31.5)$ \\
\hline $80-89$ & 161(31.9) \\
\hline $90-99$ & $89(17.6)$ \\
\hline $100-117$ & $13(2.6)$ \\
\hline \multicolumn{2}{|l|}{ Total cholesterol (mm /L) } \\
\hline $1-4.9$ & $365(72.3)$ \\
\hline $5-8.0$ & $140(29.7)$ \\
\hline \multicolumn{2}{|l|}{ Random blood glucose } \\
\hline$<11 \mathrm{mmol} / \mathrm{L}$ & $486(96.2)$ \\
\hline$\geq 11 \mathrm{mmol} / \mathrm{L}$ & $19(3.8)$ \\
\hline \multicolumn{2}{|l|}{ Body Mass Index } \\
\hline Less than 18.5 (Underweight) & $41 \quad(8.1)$ \\
\hline $18.5-25$ (Normal) & $217(43.0)$ \\
\hline Over $25-29.9$ ( Overweight) & $165(15.7)$ \\
\hline Over $30-34.9$ ( Obese) & $53(10.5)$ \\
\hline$\geq 35-39.9$ & $17(3.4)$ \\
\hline$\geq 40$ & $12(2.9)$ \\
\hline \multicolumn{2}{|l|}{ Waist Circumference } \\
\hline \multicolumn{2}{|l|}{ Male $\mathrm{N}=193$} \\
\hline$\leq 102 \mathrm{~cm}$ & $162(83.9)$ \\
\hline$>102 \mathrm{~cm}$ & $31 \quad(16.0)$ \\
\hline Mean & $87 \pm 13.1$ \\
\hline \multicolumn{2}{|l|}{ Female $\mathrm{N}=312$} \\
\hline$\leq 88 \mathrm{~cm}$ & $152(48.7)$ \\
\hline$>88 \mathrm{~cm}$ & $160(51.3)$ \\
\hline Mean & $88 \pm 11.6$ \\
\hline
\end{tabular}

*Totals do not add up to100\% because of multiple co-morbidities 


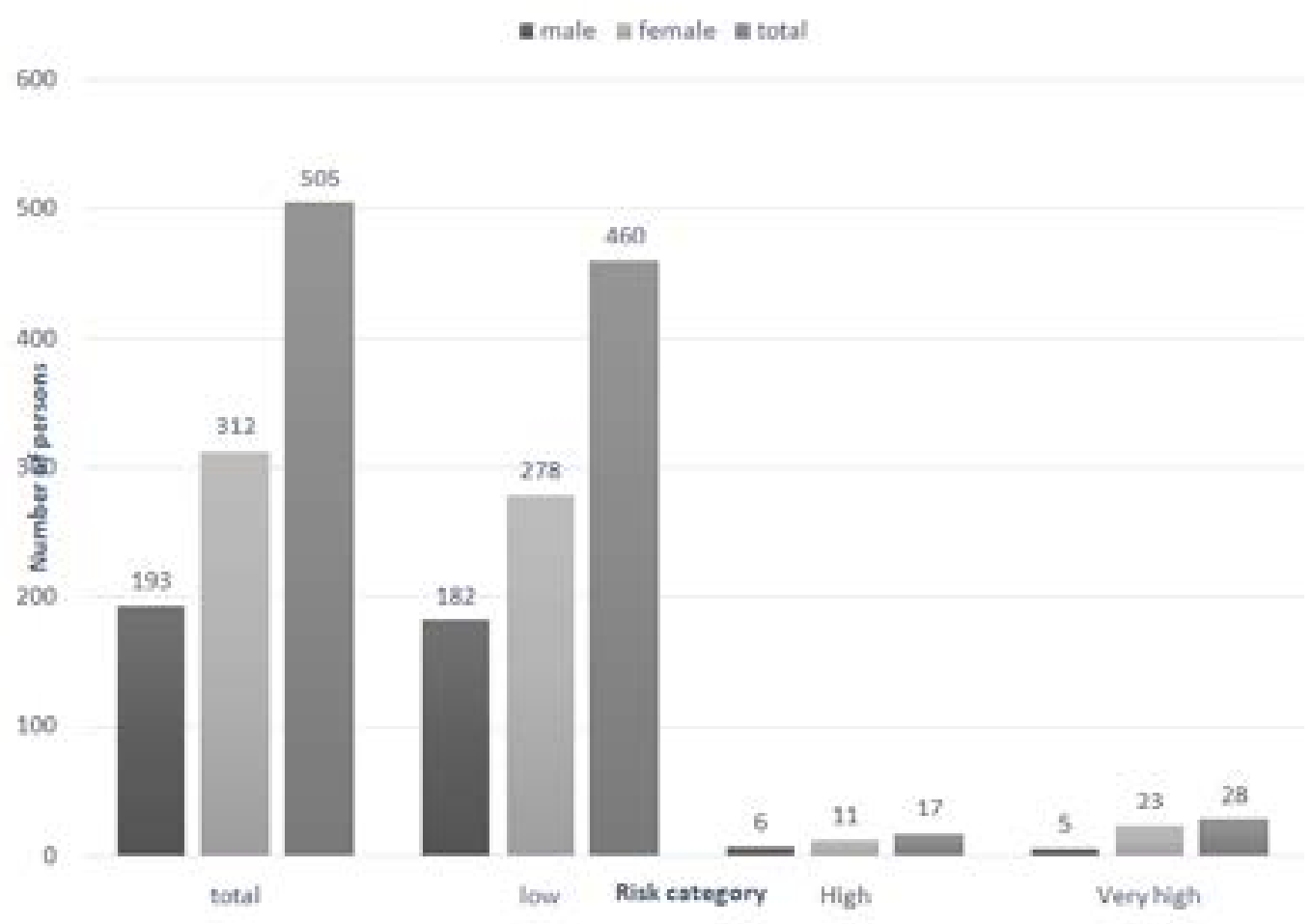

Figure 1:-Risk category of subjects

and blood sugar levels were used in a multinomial logistic regression analysis to predict cardiovascular risk score. The prediction model was statistically significant, Chi Square, 321.089.df 40,P=0.001 NagelkerkeR ${ }^{2}, 0.734$. For the high risk group, systolic blood pressure and random blood sugar were the highest predictors of high risk for cardiovascular disease OR 1.166(1.114-1.221) $\mathrm{P}=0.001$ and 1.159(1.016-1.312) $\mathrm{P}=0.001$ respectively. Systolic blood pressure and advancing age had the highest predictive value in the very high risk group OR 1.369(1.2101.510); 3.164(1.069-13.299) respectively. The detailed parameter estimates of the prediction model is shown in Table 3

Discussion

The World Health Organization / International Soci- 
Table 3- Multinomial regression analysis of independent variables and risk score rural of community dwellers

\begin{tabular}{|c|c|c|c|c|c|c|c|c|c|}
\hline \multirow[t]{2}{*}{ Model } & & \multirow[t]{2}{*}{$\mathbf{B}$} & \multirow[t]{2}{*}{ Se b } & \multirow[t]{2}{*}{ Wald } & \multirow[t]{2}{*}{ df } & \multirow{2}{*}{$\begin{array}{l}P \\
\text { value }\end{array}$} & \multirow[t]{2}{*}{ Exp. B } & \multicolumn{2}{|c|}{$95 \% \mathrm{CI}$} \\
\hline & & & & & & & & Lower & Upper \\
\hline \multirow[t]{11}{*}{ High } & Intercept & -35.641 & 4.315 & 68.208 & 1 & .000 & & & \\
\hline & Age & .257 & .223 & 1.322 & 1 & .250 & 1.292 & .869 & 2.022 \\
\hline & Sex & -.013 & .466 & .001 & 1 & .978 & .987 & .396 & 2.459 \\
\hline & Smoking status & -1.394 & .946 & 2.172 & 1 & .141 & .248 & .005 & 52.753 \\
\hline & Alcohol intake & .074 & .253 & .086 & 1 & .770 & 1.077 & .656 & 1.767 \\
\hline & Physical activity & -.086 & .641 & .018 & 1 & .893 & .917 & .261 & 3.224 \\
\hline & Chronic illness & -2.298 & 22295.598 & .000 & 1 & 1.000 & .100 & .000 & \\
\hline & $\begin{array}{l}\text { Systolic blood } \\
\text { pressure }\end{array}$ & .154 & .023 & 43.585 & 1 & .000 & 1.166 & 1.114 & 1.221 \\
\hline & $\begin{array}{l}\text { Diastolic blood } \\
\text { pressure }\end{array}$ & -.003 & .020 & .017 & 1 & .897 & .997 & .958 & 1.038 \\
\hline & Total cholesterol & -.241 & .296 & .666 & 1 & .414 & .786 & .440 & 1.402 \\
\hline & $\begin{array}{l}\text { Random blood } \\
\text { sugar }\end{array}$ & .147 & .067 & 4.809 & 1 & .028 & 1.159 & 1.016 & 1.322 \\
\hline \multicolumn{10}{|c|}{ Very high } \\
\hline & Intercept & -63.873 & 22295.597 & .000 & 1 & .998 & & & \\
\hline & Age & 1.325 & .644 & 4.235 & 1 & .040 & 3.764 & 1.065 & 13.299 \\
\hline & Sex & .899 & .924 & .947 & 1 & .331 & 2.456 & .402 & 15.015 \\
\hline & Smoking status & -.661 & 2.361 & .078 & 1 & .779 & .516 & .005 & 52.753 \\
\hline & Alcohol intake & -.447 & .581 & .591 & 1 & .442 & .640 & .205 & 1.998 \\
\hline & Physical activity & -1.332 & 1.197 & 1.237 & 1 & .266 & .264 & .025 & 2.759 \\
\hline & Chronic illness & -2.298 & 22295.598 & .000 & 1 & 1.000 & .100 & .000 &. \\
\hline & $\begin{array}{l}\text { Systolic blood } \\
\text { pressure }\end{array}$ & .314 & .050 & 38.929 & 1 & .000 & 1.369 & 1.240 & 1.510 \\
\hline & $\begin{array}{l}\text { Diastolic blood } \\
\text { pressure }\end{array}$ & -.017 & .043 & .165 & 1 & .684 & .983 & .903 & 1.069 \\
\hline & Total cholesterol & 1.070 & .656 & 2.666 & 1 & .103 & 2.916 & .807 & 10.538 \\
\hline & $\begin{array}{l}\text { Random blood } \\
\text { sugar }\end{array}$ & .357 & .233 & 2.359 & 1 & .125 & 1.429 & .906 & 2.254 \\
\hline
\end{tabular}

Dependent variable $=$ risk score. The reference category is: low risk score.

ety of hypertension risk assessment chart was the major instrument used for this study. This is a region specific validated instrument using 5 risk factors- systolic blood pressure, age, gender, total non- fasting cholesterol level, smoking and diabetes status to predict CV risk. ${ }^{9}$ The female predominance in the population surveyed may be due to the fact that the study was conducted in the community health center which usually have mostly women in attendance. The fact that majority of the participants were in the 61-70 age group, followed by those who were above 70 years is expected since focus of the study was cardiovascular disease, a condition associated with increasing age. That more than one quarter of the subjects were either moderate or heavy consumers of alcohol has serious implications in development of cardiovascular disease in this population. The claim of being physically active by majority of subjects is understandable because the major economic activity in this community is farming and all residents, irrespective of age and gender engage in farming on a daily basis, the only exception being on the community market day (Eke day). More than 40\% and nearly 30\% of subjects had systolic and diastolic blood pressures respectively beyond normal values. This is quite high compared to national estimates. A meta-analysis of hypertension prevalence studies in Nigeria put the rate at $22 \%(95 \%$, C I. $17-27 \%) .{ }^{20}$ The apparently high rate observed in this study, may be due to the fact that the study stipulated an age cut off point and in view of the purpose of the study, persons who have reasons to believe that they may be at risk were more likely to present themselves for screening. Almost 30\% of screened subjects had total cholesterol beyond normal limits, although for most of these, the increases were marginal. The dietary pattern of palm oil based food common in this part of the country may be responsible for this observation. Therefore interventions focused on dietary modifications should be quite effective in this setting. Almost 20\% had BMI values exceeding normal. Obesity is a secondary risk factor for cardiovascular disease, therefore these persons would need some form of intervention. The proportion of persons with moderate to high cardiovascular risk as seen from the general screening exercise is comparable to 
other studies. ${ }^{21}$

Generalization of the results from this study is limited by the fact that the WHO/ISH risk assessment charts may underestimate risk in specified population groups including very obese patients and elderly female population .Another limitation is the non-random selection of study participants.

\section{Conclusion}

Community pharmacists are capable of performing macro level preventive health activities and the unique characteristics of community pharmacists can be explored to support community based screening.

\section{Ethical approval}

Ethical approval was obtained from the Delta State University Health Ethics Commitee, Oghara, Delta State, Nigeria.

\section{Acknowledgement}

The authors are grateful to his royal Highness Evangelist Osanwuta J P, the EZHIE 1 of Ezionum Kingdom, for authorizing excellent community mobilization for this project. This work was funded by Tertiary Education Trust Fund (TETFUND).

\section{Conflict of interest}

None declared.

\section{References}

1. American Heart Association(AHA) (2011) - Statistical Fact Sheet 2012 update. Available at http://www.heart. org/idc/groups/heartpublic/@wcm/@sup/@smd/ documents/downloadable/ucm_31957.pdf.Accessed 15/3/13.

2. Center for Disease Control and Prevention (CDC) (2011) - Heart Disease Facts and Statistics Available at http://www.cdc.gov/heartdisease/statistics.htm.Accessed 14/6/13.

3. Alan SG, Dariush M, Veronique LR, Emelia J B, Jarelt D, Michael J and Melanie, B.T. Writing group members (2014) - Heart Disease and Stroke Statistics - 2014 Update - A report from the American Heart Association. Available at http://www.circ.ahajournals.org. Accessed $7 / 1 / 15$.
4. World Heart Foundation(WHF) (2014) - Heart disease statistics. Available at http://www.theheart foundation. org/heart-disease-facts/heart-disease statistics/. Accessed 15/1/15.

5. World Health Organization(WHO) (2011). Cardiovascular disease fact sheet. Available from http://www.who. int/mediacenter/factsheets/fs317/en/ index.html. Accessed 15/1/15.

6. World Health Organization (WHO) (2015) - Risk factors. Available at http/www. who.int_topics_risk_factors, Accessed 15/2/15.

7. Grundy SM., Pasternak R., Greenland P, Smith S and Furster V - Assessment of Cardiovascular risk by use of multiple risk factor equation: A statement for healthcare professionals from the American Heart Association and the American College of Cardiology. Circulation, 1999; 100: 1481-1492.

8. Gershi BJ,Sliwa K, Bongani MM and Yusuf S - The epidemic of cardiovascular disease in the developing world: global implications. Eur. Heart J. 2010; 32:642-648. 9. World Health Organization (WHO) (2007) - Prevention of Cardiovascular disease - guidelines for assessment and management of cardiovascular risk. WHO Geneva ISBN 9789241547178.

10. World Health Organization (WHO) (2002) -WHO CVD risk management package for low and medium resource settings. Geneva, World Health Organization.

11. Santchi V, Chiolero A, Burnand B, Colosimo A.L. and Paradis, G. - Impact of pharmacist care in the management of cardiovascular disease risk factors. Arch. Intern. Med. 2011; 171(16):1411-1453.

12. Bagwell A, Skelley JW, Saad L, Wooley T and Dugan D. - The role of the clinical pharmacist in modifying cardiovascular risk factors. Innov. Pharm. 2013; 4; (3):129 Available at http/z.umol.edu/innovations.

13. Willis, A., Rivers, P., Gray, J.L. and Khunti, K. The Effectiveness of screening for Diabetes and cardiovascular Disease risk factors in a community Pharmacy Setting. PLos One. 2014; 9(4):e91157.doi:1371/journal. pone.0091157.

14. Youmans SL, Vogt EM and Yang KY-Utilization of community pharmacies: implications for health care delivery. Harvard Health Policy Review, 2006; 7(1):180-185.

15. Chiazor IE, Evans M, vanWoerden $\mathrm{H}$ and Oparah A C (2015) A Systematic Review of community phar- 
macist' interventions in reducing major risk factors for cardiovascular Disease. Value in Health Reg. Issues 2015; 7C: 9-21. Available at www.elsevier.com/locate/vhri, Accessed 25/6/15

16. Federal Republic of Nigeria - 2006 Population Census, National Bureau of Statistics. Federal Republic of Nigeria, Official gazette. (2007). 24 (94).

17. SPSS software (SPSS $®)$ version 19.0 (SPSS, Inc., 2010) 18. Tabanick BG, Fidell L S, Osterlind SJ, -Using multivariate statistics. US, Allyn\& Bacon, Boston, 2001

19. American college of cardiology foundation and American Heart association (ACCF/AHA) (2010) guideline for assessment of cardiovascular risk in asymptomatic adults. Available at myamericanheart.org.Accessed 18/7/2016 20. Ekwunife I O. and Agunwa NCA (2011) - meta-analysis of prevalence rate of hypertension in Nigerian populations. J. Public Health Epidemiol. 2011; 3(13):604-607. 21. Otgontuya D, Oum S, Buckley BS and Bonita R (2013) - Assessment of total cardiovascular risk using WHO/ ISH risk prediction charts in three low and middle income countries in Asia. BMC Public Health. 2013; 13:539. Available at http//www.biomedcentral.com/1471$2458 / 13 / 539$. 